\title{
Detailed characterization of, and clinical correlations in, 10 patients with distal deletions of chromosome 9p
}

Xueya Hauge, $P h D^{1}$, Gordana Raca, $P h D^{2}$, Sara Cooper, $M S^{2}$, Kristin May, $P h D^{3}$, Rhonda Spiro, $M D^{4}$, Margaret Adam, $M D^{2}$, and Christa Lese Martin, $P h D^{2}$

\begin{abstract}
Purpose: Deletions of distal $9 p$ are associated with trigonocephaly, mental retardation, dysmorphic facial features, cardiac anomalies, and abnormal genitalia. Previous studies identified a proposed critical region for the consensus phenotype in band $9 \mathrm{p} 23$, between $11.8 \mathrm{Mb}$ and $16 \mathrm{Mb}$ from the $9 p$ telomere. Here we report 10 new patients with $9 p$ deletions; 9 patients have clinical features consistent with $9 p-$ syndrome, but possess terminal deletions smaller than most reported cases, whereas one individual lacks the 9p- phenotype and shows a 140-kb interstitial telomeric deletion inherited from his mother. Methods: We combined fluorescence in situ hybridization and microarray analyses to delineate the size of each deletion. Results: The deletion sizes vary from $800 \mathrm{~kb}$ to $12.4 \mathrm{Mb}$ in our patients with clinically relevant phenotypes. Clinical evaluation and comparison showed little difference in physical features with regard to the deletion sizes. Severe speech and language impairment were observed in all patients with clinically relevant phenotypes. Conclusion: The smallest deleted region common to our patients who demonstrate a phenotype consistent with $9 p-$ is $<2 \mathrm{Mb}$ of 9 pter, which contains six known genes. These genes may contribute to some of the cardinal features of 9p deletion syndrome. Genet Med 2008:10(8): 599-611.
\end{abstract}

Key Words: $9 p$ deletion, FISH, genotype-phenotype correlation, aCGH

The $9 \mathrm{p}$ deletion syndrome is characterized by trigonocephaly, moderate to severe mental retardation, low-set, malformed ears, and dysmorphic facial features, such as up-slanting palpebral fissures and a long philtrum. ${ }^{1,2}$ Furthermore, abnormal genitalia are found in some $9 \mathrm{p}-$ patients who have a chromosomal complement of $46, \mathrm{XY},{ }^{3}$ and hypopigmentation has also been described in two independent studies. ${ }^{4,5}$ Since the original report of the syndrome in $1973,{ }^{6}$ over 140 cases of $9 p$ deletion have been documented. The breakpoints occur in bands from 9p22 to 9p24, and the large majority of patients have either terminal deletions or translocations involving another chromosome.

Previous studies have delineated the size of $9 p$ deletions in an attempt to develop genotype-phenotype correlations. In one large study, Christ et al., ${ }^{2}$ characterized the deletion break-

\footnotetext{
From the ${ }^{1}$ Department of Biology and Physics, Kennesaw State University, Kennesaw, Georgia; ${ }^{2}$ Department of Human Genetics, Emory University School of Medicine, Atlanta, Georgia; ${ }^{3}$ Department of Pediatrics, University of Tennessee College of Medicine, Chattanooga Unit, Chattanooga, Tennessee; and ${ }^{4}$ National Birth Defect Center, Waltham, Massachusetts. Christa Lese Martin, PhD, Department of Human Genetics, Emory University School of Medicine, 615 Michael Street, Suite 301, Atlanta, GA 30322. E-mail: clmartin@genetics. emory.edu.

First two authors contributed equally to this work.

Disclosure: The authors declare no conflict of interest.

Submitted for publication December 21, 2007.

Accepted for publication April 29, 2008.

DOI: 10.1097/GIM.0b013e31817e2bde
}

points in 24 patients with visible $9 \mathrm{p}$ deletions and breakpoints at 9p22 or 9p23. Markers D9S274 (14.2 Mb from the telomere) and D9S286 $(8 \mathrm{Mb})$ were absent in all 24 patients with $9 \mathrm{p}-$, whereas D9S285 $(16 \mathrm{Mb})$ was present in a subset of these patients. Thus, the minimal deleted segment in this group of patients included $16 \mathrm{Mb}$ of the $9 \mathrm{p}$ terminus. Wagstaff and Hemann $^{4}$ described a patient with typical features of $9 p-$ syndrome and an interstitial deletion between $8 \mathrm{Mb}$ and $19 \mathrm{Mb}$ of $9 \mathrm{p}$. Based on the data of Wagstaff and Hemann, ${ }^{4}$ and from their own data, Christ et al., ${ }^{2}$ modified their critical region, i.e., the distal $16 \mathrm{Mb}$ of $9 \mathrm{p}$, and concluded that the critical region for the $9 \mathrm{p}-$ syndrome lies in an $\sim 8-\mathrm{Mb}$ region between D9S285 and D9S286, encompassing bands 9p22-9p23.

Among a number of recent publications, Muroya et al.,7 determined the breakpoints in six patients with $9 p$ deletions using microsatellite markers. Of these, two patients who did not show the typical phenotype observed with $9 \mathrm{p}$-syndrome had small deletions $(\sim 3 \mathrm{Mb})$ of 9pter, as the marker at $2.8 \mathrm{Mb}$ (D9S1136) from 9pter was present, whereas the marker at 2.1 $\mathrm{Mb}$ (D9S143) was absent. But neither of these cases had pure deletions: one had a duplication of $9 p$ (9p12-p24), and the other had a trisomy of $4 \mathrm{p}$ ( $4 \mathrm{p} 13$-pter). Kawara et al., ${ }^{5}$ described one patient who had a complex translocation and insertion involving chromosomes 2 and 9p. The major clinical features of this patient included trigonocephaly, mental retardation, and facial features commonly seen in the $9 \mathrm{p}-$ syndrome. Using fluorescence in situ hybridization (FISH) analysis, the region 
deleted from $9 \mathrm{p}$ was mapped to a $6.6-\mathrm{Mb}$ region between 11.8 $\mathrm{Mb}$ and $18 \mathrm{Mb}$ of the $9 \mathrm{p}$ terminus. Based on these data and those of Christ et al., ${ }^{2}$ the authors concluded that the critical region for the $9 \mathrm{p}-$ syndrome lies in a $4.7-\mathrm{Mb}$ region between $11.4 \mathrm{Mb}$ and $16 \mathrm{Mb}$ of $9 \mathrm{p}$; they furthermore proposed cerberus-related 1 (CER1) as a candidate gene for trigonocephaly. Faas et al., ${ }^{8}$ described another patient who had a $14.8 \mathrm{Mb}$ deletion of 9pter (9p22.3-pter) and a $50.9 \mathrm{Mb}$ duplication of chromosome 9 (9p22.3-q12). The patient had trigonocephaly and facial features consistent with $9 \mathrm{p}-$ syndrome. Based on the data published by Kawara et al., ${ }^{5}$ the authors concluded that a 3.5 $\mathrm{Mb}$ region, between $11.4 \mathrm{Mb}$ and $14.9 \mathrm{Mb}$, is the critical region for $9 \mathrm{p}-$ syndrome.

In three studies ${ }^{2,5,8}$ the deletions of $9 p$ were cytogenetically visible and the breakpoints were more than $10 \mathrm{Mb}$ from 9pter. In fact, only a few cases with $9 \mathrm{p}$ deletions smaller than $10 \mathrm{Mb}$ have been reported to date, which is not unexpected, since the detection of subtle telomeric deletions presents a challenge in routine G-banded cytogenetic studies. With the availability of higher-resolution methods to detect and characterize copy number imbalances in the human genome, including FISH and array comparative genomic hybridization $(\mathrm{aCGH})$, individuals with cryptic 9p deletions have been identified in recent years. ${ }^{9-11}$

We have identified five patients with cryptic $9 p$ telomere deletions and five cases with cytogenetically visible deletions. Of these 10 new cases, 4 have pure, terminal deletions, 4 have unbalanced translocations, one has a terminal deletion and an adjacent duplication, and one has an interstitial telomeric deletion. FISH and aCGH were utilized to map the breakpoints in these cases. In addition, the clinical phenotypes of these individuals were compared. Based on our mapping data and phenotype comparisons, we have contributed to the delineation of genotype-phenotype correlations for the $9 \mathrm{p}$ deletion syndrome.

\section{MATERIALS AND METHODS}

\section{Case descriptions}

Patients were ascertained through the Clinical Cytogenetic Laboratories at Emory University and the University of Chicago and through referrals to our telomere research project. This study was carried out under protocols approved either by the Institutional Review Board at Emory University or the University of Chicago. Clinical data for patients were obtained either by physical examination or a thorough review of the medical history.

Obstetric nomenclature: pregnancies, full-term deliveres, premature deliveres, abortions (spontaneous or induced), living infants.

\section{Case 1}

Case 1 was born to a 25-year-old G2P0010 mother and a 25 -year-old father. The patient was born at 40 weeks' gestation by cesarean section. His birth weight was $3.1 \mathrm{~kg}$ (25th-50th centile) with a birth length of $47 \mathrm{~cm}$ (25th centile). Aside from mild jaundice, there were no neonatal problems.
Case 1 has long-standing difficulties with excessive weight gain. At 1 year of age, his weight was $16.3 \mathrm{~kg}$ ( $\gg 97$ th centile; 50th centile for 3-3/4 years). He also has experienced an unusual sleep pattern; once or twice every few months he will have episodes in which he sleeps between 12 and 48 hours. During these times his family cannot rouse him. Afterward he has slurred speech and regression in both emotional and developmental milestones. It takes him about 7-10 days to fully recover. A head magnetic resonance image (MRI) was normal, but the patient does have a known seizure disorder. It is unclear whether these episodes of sleeping are a manifestation of seizure activity.

On physical examination at 4 years, Case 1 weighed $23.6 \mathrm{~kg}$ ( $\gg 97$ th centile; 50 th centile for $7-1 / 4$ years). His height was $95.9 \mathrm{~cm}$ (50th centile), and his head circumference was $49.5 \mathrm{~cm}$ (50th centile). No dysmorphic features were noted. Aside from his weight and mild hypotonia, his physical examination was normal, as was a cardiology evaluation.

Case 1 had a normal 46, XY karyotype at 625 bands. Methylation studies for Prader-Willi syndrome were negative and he had a normal muscle biopsy. Molecular studies for fragile X and FRAXE were normal. Telomere FISH analysis demonstrated a deletion of the 9p telomere. Parental studies showed that his mother also had this same $9 p$ deletion.

The mother has had several medical issues herself. She has a history of petit mal seizures with onset at 13 years. She has been seizure-free off antiseizure medication since age 18 . She is developmentally normal.

\section{Case 2}

Case 2 is now a 6 -year-old girl born at $37-1 / 2$ weeks by repeat C-section. Her birth weight was $2.72 \mathrm{~kg}$ (10th-25th centile) with a birth length of $45.7 \mathrm{~cm}$ (5th centile). Although she had failure to thrive as an infant, this has since resolved. During childhood she was diagnosed with moderate mental retardation. She has also been described as having autistic-like features. A physical examination demonstrated arching eyebrows, a long philtrum with thin upper lip, posteriorly rotated and low-set ears, and clinobrachydactyly. No major malformations have been noted, but she does have a history of mild hypotonia. Formal vision and hearing tests have been normal. A routine chromosome analysis was normal, as was a molecular study for fragile $\mathrm{X}$. The patient was found to have a de novo cryptic deletion of $9 \mathrm{p}$ by telomere FISH analysis.

\section{Case 3}

Case 3 was the product of a 41.5 -week gestation. He was born by cesarean section secondary to failure to progress and macrocephaly. His birth weight was $4.6 \mathrm{~kg}$ (>95th centile) with a length of $54.6 \mathrm{~cm}$ (95th centile) and a head circumference of $38.1 \mathrm{~cm}$ (98th centile). He had no problems after birth. As an infant, he had difficulties with multiple episodes of otitis media and sinusitis, which required the placement of myringotomy tubes and adenoidectomy, respectively. Hearing before ear tube placement was assessed as "adequate." He has had 
neither formal cardiac or renal assessments, nor any head imaging studies.

In terms of development, Case 3 was notably delayed (see Table 1). He had been given a presumptive diagnosis of pervasive developmental disorder not otherwise specified.

His physical examination was significant for generalized overgrowth and dysmorphic features. At 28 months his weight was $19 \mathrm{~kg}$ ( $\gg 95$ th centile) with a height of $98.5 \mathrm{~cm}$ ( $>95$ th centile) and a head circumference of $53.8 \mathrm{~cm}$ ( $>98$ th centile). He had mild midline prominence of the forehead with a fading glabellar hemangioma. He was noted to have pseudostrabismus with an otherwise normal ophthalmologic evaluation. He had narrow and down-slanting palpebral fissures, periorbital fullness, and medial eyebrow flare. He had posteriorly rotated ears, which were $6 \mathrm{~cm}$ (>97th centile) bilaterally. The patient also had an upturned bulbous nasal tip, with a wide nasal bridge and small nares. His cheeks were full with a small mouth and tented upper lip. He had spatulate fingertips and short fifth digits. His hallices were short and wide. He had mild hypotonia. He had no history of seizures and an EEG was normal. He had a normal G-banded chromosome analysis at 600 bands. Telomeric FISH analysis demonstrated a deletion of the $9 p$ telomere region.

\section{Case 4}

Case 4 was born to a 28 -year-old G4P3 mother. A fetal echocardiogram showed an abnormal azygos vein. Case 4 was born at 36 weeks' gestation by cesarean section due to double-footling breech positioning. Her birth weight was $3.003 \mathrm{~kg}$ (75th90th centile) with a length of $51 \mathrm{~cm}(>90$ th centile) and a head circumference of $35.5 \mathrm{~cm}$ ( $>90$ th centile). She was noted to have dysmorphic features, including a prominent metopic ridge with trigonocephaly. She had short palpebral fissures and ocular hypotelorism. Her ears were low-set and small, measuring $2.7 \mathrm{~cm}$ (<third centile) bilaterally. She had a prominent nose with short columella and a high arched palate. She also had hypoplastic and low-set nipples, prominent labia minor, and an anteriorly placed but patent anus. The fingers were long and slender with fifth digit clinodactyly. The feet measured 7.7 $\mathrm{cm}$ (>90th centile) bilaterally, with the second and fourth toes overlapping the third toes bilaterally. She was noted to be hypotonic.

Postnatal imaging studies are listed in Table 2. A head computed tomography demonstrated fusion of the metopic suture with a significant increase in extra-axial space, which appeared to be subarachnoid. There was a marked reduction in the folding of the cortex, with smooth frontal lobes and significantly immature morphology of the Sylvian fissure. The corpus callosum appeared to be intact, but the cerebellum was small. A 3-dimensional reconstruction revealed severe narrowing of the posterior choana bilaterally, consistent with bony choanal atresia. The roof of the ethmoid anterior to the crista galli was absent, with a possible encephalocele. Case 4 succumbed in the neonatal period. G-banded chromosome analysis demonstrated a de novo 46, XX, der(9)t $(9 ; 15)(\mathrm{p} 24.3 ; \mathrm{q} 25)$ karyotype.

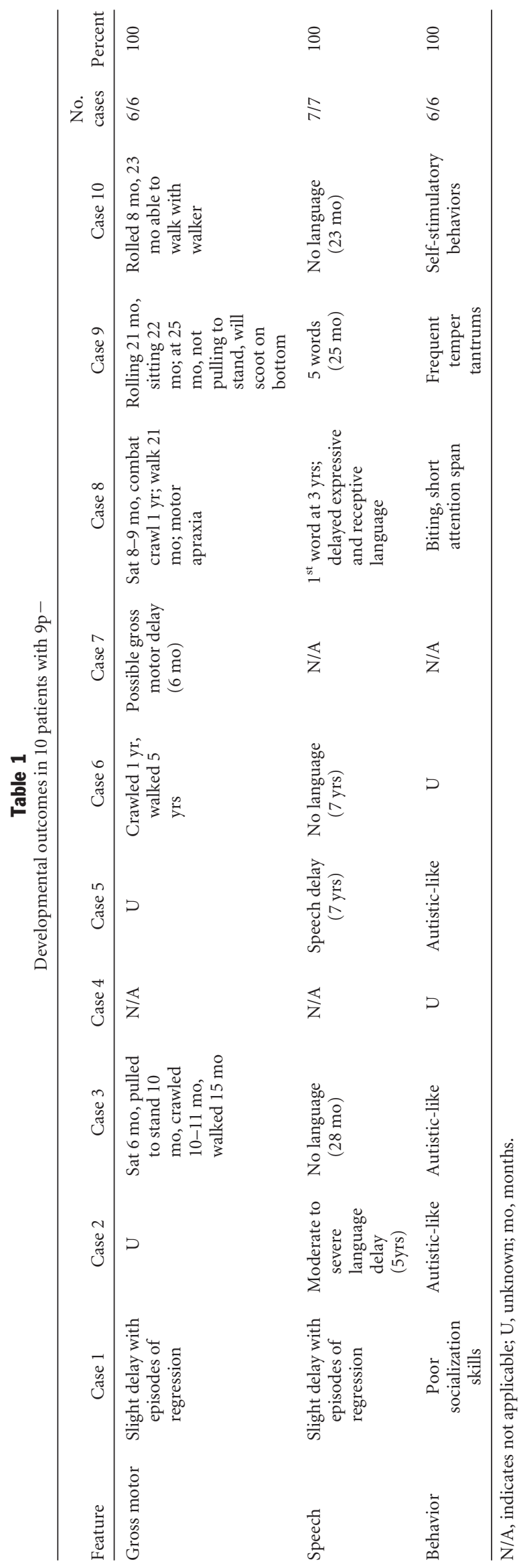


Table 2

Postnatal major malformations in ten patients with $9 \mathrm{p}-$

\begin{tabular}{|c|c|c|c|c|c|c|c|c|c|c|}
\hline Organ Systems & Case 1 & Case 2 & Case 3 & Case 4 & Case 5 & Case 6 & Case 7 & Case 8 & Case 9 & Case 10 \\
\hline Brain/skull & Nl by MRI & $\mathrm{Nl}$ & NA & $\begin{array}{l}\text { Reduced folding of } \\
\text { the cortex with } \\
\text { extraaxial fluid; } \\
\text { bony choanal } \\
\text { atresia }\end{array}$ & $\mathrm{Nl}$ by CT & NA & $\begin{array}{l}\text { Structurally } \\
\text { Nl by CT }\end{array}$ & Nl by MRI & Nl by US & Nl by MRI \\
\hline Ophthalmology & NA & $\mathrm{Nl}$ & $\mathrm{Nl}$ & NA & NA & NA & $\mathrm{Nl}$ & $\mathrm{Nl}$ & $\mathrm{Nl}$ & NA \\
\hline Cardiac & NA & $\mathrm{Nl}$ & NA & $\begin{array}{l}\text { R Ao arch and } \\
\text { VSD }\end{array}$ & $\mathrm{Nl}$ & NA & $\begin{array}{l}\text { VSD, PDA, } \\
\text { PFO }\end{array}$ & NA & NA & NA \\
\hline Genitourinary & NA & $\mathrm{Nl}$ & NA & $\begin{array}{l}\text { Bilateral } \\
\text { hydronephrosis }\end{array}$ & $\mathrm{Nl}$ & NA & $\mathrm{Nl}$ & $\begin{array}{l}\text { Ventral deficiency } \\
\text { of foreskin, R } \\
\text { cryptorchidism }\end{array}$ & $\begin{array}{l}\text { R cystic metanephric } \\
\text { mass with R atretic } \\
\text { ureter }\end{array}$ & $\begin{array}{l}\text { Min L renal } \\
\text { fullness }\end{array}$ \\
\hline
\end{tabular}

Ao indicates aortic; CT, computed tomography; L, left; Min, minimal; MRI, magnetic resonance imaging; NA, not assessed; Nl, normal; PDA, patent ductus arteriosus; PFO, patent foramen ovale; R, right; US, ultrasound; VSD, ventriculoseptal defect.

\section{Case 5}

Case 5 was initially evaluated because of a history of regression and speech delay. She was a twin delivered at 38 weeks' gestation with a birth weight of $2.78 \mathrm{~kg}$ (25th centile). She initially began speaking single words at 1 year of age; however, by 2 years of age she lost her words altogether. She subsequently slowly learned to speak again, such that by 5 years of age she said 12 words. She was noted to have poor eye contact and impairment in social interactions, and was therefore diagnosed with autism (autism quotient 104, which is at the 61st centile).

On examination she was noted to have several dysmorphic features, including brachycephaly, down-slanting palpebral fissures with deep-set eyes, midface hypoplasia, long philtrum with thin upper lip, moderate hypotonia, and a wide-based and unsteady gait. A formal ophthalmology evaluation demonstrated exotropia. Cardiac, renal, and skeletal systems were formally assessed with no abnormalities found. The patient is not known to have seizures. Formal hearing tests were normal. She has no known behavioral problems. She had a normal G-banding analysis at the 650-band level. Telomere FISH analysis demonstrated monosomy for 9 pter and trisomy for 3 pter.

\section{Case 6}

Case 6 is now a 7 -year-old girl born to a 27 -year-old G3P2002 mother. She was born at term with a birth weight of $3.49 \mathrm{~kg}$ (50th-75th centile). She was noted to have dysmorphic features after birth. An abdominal ultrasound demonstrated somewhat enlarged adrenal glands. An initial chromosome analysis detected additional material on the short arm of chromosome 9 .

As a child, Case 6 had multiple episodes of otitis media, necessitating the placement of pressure-equalizing tubes (PET) on approximately three occasions. She was noted to have mild hearing loss, presumed to be conductive in nature. She was noted to have mild gastroesophageal reflux, and an upper endoscopy demonstrated esophageal diverticula. Case 6 has developmental delay (see Table 1 for details).
At age 7 years Case 6 was noted to have microcephaly with a head circumference of $48 \mathrm{~cm}$ ( $<$ second centile). Her weight was $24 \mathrm{~kg}$ (50th-75th centile) with a height of $111.1 \mathrm{~cm}(<5$ th centile, 50th centile for 5-1/2 years). She had mild hypertelorism with low-set eyebrows. Her ears were mildly low-set and posteriorly rotated with thick helices and fleshy lobules (Fig. 1,
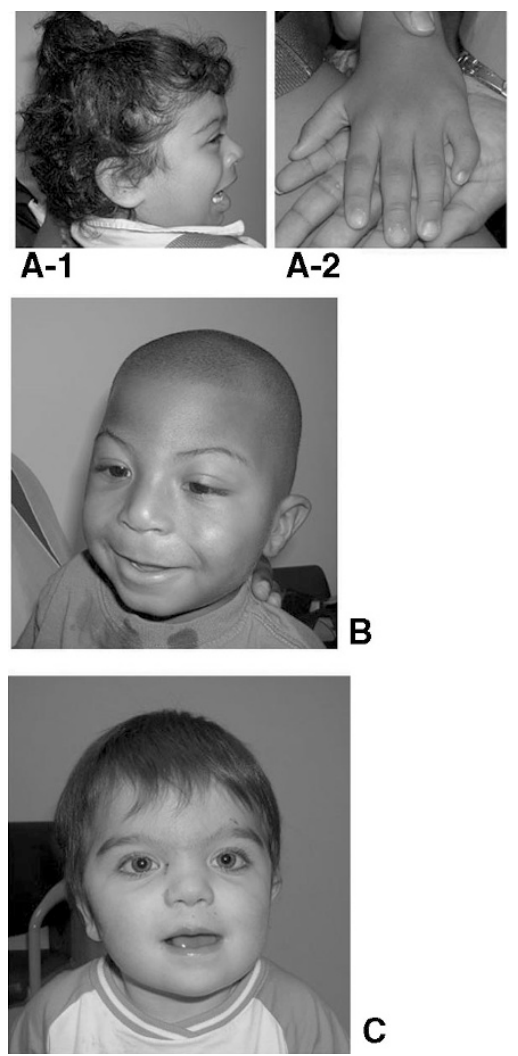

Fig. 1. A, Case 6 at 7 years of age. Note the mildly low-set and posteriorly rotated ears with thick helices and fleshy lobules, as shown in 1A-1. Also note clinobrachydactyly of the fifth digit (Fig. 1A-2). B, Case 9 at 2 years of age. Note trigonocephaly, thin and arching eyebrows, low-set ears that are otherwise normally formed, and long and thin philtrum with thin upper lip. C, Case 10 at 23 months of age. Note the hirsute forehead with mild synophrys and hypertelorism. 
A-1). She had a smooth philtrum with a thin upper lip and peg-shaped teeth. She was noted to have mildly hypoplastic labia majora. Her palms were long with shortening of the fifth metacarpals bilaterally. She had clinobrachydactyly of the fifth fingers bilaterally and hyperextensibility of the proximal interphalangeal joints of the fingers. She had a wide space between her first and second toes bilaterally, with varus positioning of her left foot. She had hypoplastic fifth toenails. She also had hypotonia. Repeat chromosome analysis showed a de novo 46, XX, add (9)(p24) karyotype. Further analysis using telomeric FISH demonstrated a deletion of the $9 p$ telomere and subsequent aCGH analysis revealed the additional material to be a duplication of material from $9 \mathrm{p}$.

\section{Case 7}

Case 7 was born at 32 weeks secondary to preeclampsia in her surrogate mother. The biological mother was 37 years of age. Chromosome analysis on amniotic fluid performed due to maternal age demonstrated a deletion of $9 p$. Postnatally, Case 7 was found to have an apical VSD, patent foramen ovale, and patent ductus arteriosus. A head computed tomography scan demonstrated mild hypodensity involving the parietal convexities. There was no follow-up head MRI. The patient was also noted to have dysmorphic features, including a hirsute forehead, up-slanting palpebral fissures, thin upper lip with downturned corners of the mouth, widely spaced nipples, and tapered fingers with normal creases. Her tone appeared normal. At 6 months of age, she was noted to have possible gross motor delay. A blood chromosome analysis demonstrated a de novo 46, XX, del(9)(p23) karyotype, which was confirmed by telomere FISH.

\section{Case 8}

Case 8 was born to a 33-year-old G2P0010 mother at 41-3/7 weeks' gestation. His birth weight was $3.435 \mathrm{~kg}$ (50th-75th centile) with a length of $57.2 \mathrm{~cm}$ (>90th centile) and a head circumference of $33.7 \mathrm{~cm}$ (50th centile). After birth he was noted to have ventral deficiency of his foreskin with chordee and right cryptorchidism. At 2 years of age he experienced a seizure, initially believed to be a febrile seizure; however, he went on to develop a seizure disorder that appeared to be a variant of Landau-Kleffner. An EEG done at age 4 years 9 months demonstrated copious seizure discharges lasting 1.5-2 seconds each, bilaterally. A head MRI was normal. He was also noted to be hypotonic.

Case 8 has been diagnosed with motor apraxia (see Table 1 for details). At one point a diagnosis of PDD was entertained. Case 8 has been noted to have significant behavioral issues, including aggressive behaviors (biting at school), frequent outbursts, and a short attention span.

On physical examination, Case 8 has been noted to have a narrow, triangular shape to his face, a smooth philtrum, overcrowding of his lower teeth, pes planus, and long, narrow feet, in addition to the genital abnormalities described above. An ophthalmology evaluation as an infant was concerning for ocular albinism with latent nystagmus; however, a reexamination in childhood revealed resolution of the albinism with a completely normal examination. He also experienced multiple episodes of otitis media as a child, although his formal hearing evaluation was normal. A high-resolution G-banding analysis detected a 46, XY, del(9)(p24) karyotype, which was shown to be an unbalanced translocation between $9 \mathrm{p}$ and $20 \mathrm{p}$ by telomere FISH. aCGH did not identify any other imbalances.

\section{Case 9}

Case 9 was born to a 24-year-old G2P1001 mother. A fetal ultrasound at approximately 25 weeks' gestation revealed an abdominal cystic mass, which appeared to grow slightly during the pregnancy. The pregnancy was complicated by maternal preeclampsia; labor was therefore induced at 32 weeks' gestation. At birth the patient weighed $3.115 \mathrm{~kg}$ ( $\gg 90$ th centile) with a length of $46 \mathrm{~cm}$ (75th-90th centile) and a head circumference of $31.5 \mathrm{~cm}$ (75th-90th centile). Postnatally a barium enema revealed that all the bowel was on the left side with left microcolon. Upon surgical exploration a cyst was found connected to a malrotated right kidney. Both kidneys were present in the midline, and the right ureter was completely atretic. Abdominal malrotation was also noted. The cyst was removed and the right ureter reconstructed.

Although a neonate, Case 9 was noted to have clouded corneas with concern for possible cataracts. A repeat ophthalmology evaluation at 6 months of age demonstrated resolution of these issues with a completely normal eye examination. Case 9 had several episodes of otitis media that required PET. His hearing evaluation has been normal because of tube placement.

In terms of development, Case 9 has been behind (see Table 1 for details). He has multiple temper tantrums and frustration, some of which is attributed to his inability to communicate effectively.

On physical examination at 25 months of age, Case 9 weighed $13.17 \mathrm{~kg}$ (50th-75th centile). His length was $90.5 \mathrm{~cm}$ (75th centile) with a head circumference of $47.9 \mathrm{~cm}$ (25th-50th centile). He was noted to have trigonocephaly with posterior plagiocephaly, midfacial hypoplasia, thin and arching eyebrows, low-set ears that are otherwise normally formed, a long and thin philtrum with thin upper lip, and mild hypotonia (Fig. 1, B). Because of his developmental issues, a chromosome analysis and telomere FISH study were done. High-resolution chromosome analysis was normal, but telomere FISH revealed an unbalanced translocation with a deletion of $9 \mathrm{p}$ and a duplication of 20p. aCGH confirmed the FISH result and did not identify any other imbalances. Parental studies demonstrated that the mother carries the balanced form of this telomeric translocation.

\section{Case 10}

Case 10 was born to a 27-year-old G3P2002 mother at 37 weeks' gestation. The pregnancy was uncomplicated, except for preterm labor starting at 34 weeks, which was treated with terbutaline. Her birth weight was $3.4 \mathrm{~kg}$ (90th centile). She had difficulties with gastroesophageal reflux shortly after birth and 
required a Nissen fundoplication. She subsequently experienced constipation followed by diarrhea and was ultimately diagnosed with inflammatory bowel disease. Case 10 was also noted to have significant trigonocephaly, which required craniotomy at 16 months of age. A head MRI was normal. The patient has also had multiple episodes of otitis media, though PET have never been placed. Her hearing screen at birth was normal. She has noted photosensitivity. A renal ultrasound demonstrated minimal left renal fullness, but was otherwise normal. For developmental history, please see Table 1.

Case 10 has been noted to have several dysmorphic features, including a prominent anterior fontanelle (noted at 9 months of age), hirsute forehead, a mild synophrys, hypertelorism with epicanthus inversus, low-set ears with upswept lobules, an upturned nose, a thin upper lip, widely spaced nipples, an anteriorly placed anus, generalized brachydactyly with hyperconvex nails, mildly hypoplastic toenails, and truncal hypotonia (Fig. 1, C). Growth parameters at 23 months of age were: weight $13 \mathrm{~kg}$ (75th-90th centile), length $80.2 \mathrm{~cm}$ (10th centile), and head circumference $47.5 \mathrm{~cm}$ (50th centile). Because of her large anterior fontanelle, thyroid function studies were sent, with normal thyroid stimulating hormone results at 1.0 (reference range $0.3-5.0 \mathrm{UIU} / \mathrm{mL}$ ) and a mildly low free T4 of 0.57 (reference range 1.1-2.0 ng/dL). A chromosome analysis demonstrated a de novo 46, XX, del(9)(p23) karyotype. aCGH analysis confirmed the $9 \mathrm{p}$ deletion and did not identify any other imbalances.

\section{Cytogenetic and molecular cytogenetic analyses}

G-banded chromosome analysis was performed on all 10 cases. High-resolution mapping of the breakpoints was conducted using a combination of FISH and aCGH for six cases, aCGH only for two cases (Cases 2 and 5, since only DNA samples were available) and FISH only for two cases (Cases 4 and 7, as only chromosomal cell pellets were available).

A telomere FISH panel (ToTelVysion, Abbott Molecular, Inc., Des Plaines, IL) was utilized to screen for telomeric imbalances of all chromosome ends. For FISH analysis in the targeted $9 \mathrm{p}$ region, molecular ruler clones, spaced $500 \mathrm{~kb}-1$ $\mathrm{Mb}$ apart and covering the most distal $14 \mathrm{Mb}$ of $9 \mathrm{p}$, were used as probes to delineate the size of the deletions. Twenty-three bacterial artificial chromosomes (BAC) clones were selected from the UCSC Genome Browser May 2004 assembly (http:// genome.ucsc.edu/cgi-bin/hgGateway) and obtained from BACPAC Resources (CHORI, Oakland, CA). The clone content of most of these BACs was verified before FISH studies using polymerase chain reaction with sequence tagged site markers.

BAC DNA was prepared by an alkaline lysis miniprep method and labeled with Spectrum Orange-dUTP (Abbott Molecular, Inc., Des Plaines, IL), Spectrum Green-dUTP (Abbott Molecular, Inc., Des Plaines, IL), or diethylaminocoumarin-5-dUTP (DEAC/aqua, PerkinElmer Life and Analytical Sciences, Inc., Boston, MA) by nick translation. Hybridization and washes followed previously published procedures. ${ }^{12} \mathrm{FISH}$ was performed on metaphase chromosomes, and images were captured with a fluorescence microscope and SmartCapture software (Digital Scientific, Cambridge, UK).

A custom oligonucelotide array for aCGH analysis was designed to include 10 oligonucleotide probes for the most distal unique telomere BAC clone on chromosome 9, and the telomere clone for all other chromosome arms (Agilent, Santa Clara, CA). Proximal to this targeted telomere clone coverage, an oligonucleotide was placed every $75 \mathrm{~kb}$ for the rest of each chromosome arm, providing a resolution for measuring telomere imbalances of $\sim 50-75 \mathrm{~kb}$. Normal male and female patient genomic DNA samples, made up of a pool of DNA from 4 to 6 individuals (Promega, Madison, WI), were used as standard reference control DNAs. Preparation of test and control DNA, labeling, and hybridization were performed after the manufacturer's protocols (Agilent, Santa Clara, CA). Opposite sex controls were used, so that detection of expected gains or losses on the $\mathrm{X}$ and $\mathrm{Y}$ chromosomes could serve as internal controls for array performance. Dye-swap experiments were performed for some cases. After hybridization, slides were scanned on a GenePix 4000B scanner (Molecular Devices, Sunnyvale, CA), and the array images were captured using GenePix Pro4.0 software. The images were analyzed using BlueFuse software (BlueGnome, Cambridge, UK).

\section{RESULTS}

\section{Clinical findings}

Table 3 summarizes the pertinent clinical features observed in our 10 patients. Of these, four patients (Cases 1, 3, 8, and 9) are men, and six are women. Most of our patients exhibit dysmorphic facial features, including low-set, malformed ears (67\%), thin upper lip (86\%), long philtrum $(86 \%)$, midface hypoplasia (67\%), and arching eyebrows (33\%). Trigonocephaly was observed in three patients (38\%), and one patient, Case 3 , has midline prominence of the forehead. Sex reversal was not observed in any of our male patients, although we did observe other external genital abnormalities, such as cryptorchidism in one male patient. Of six female patients, external genital abnormalities were seen in three patients, including anteriorly placed anus. Overall, $67 \%$ of our cases had external genital abnormalities. Macrosomia was found at birth or in childhood or both in Cases 1, 3, 9, and 10.

Table 2 outlines the major malformations by organ system exhibited in the 10 patients. Notably, very few of the patients in our cohort have major malformations, such as structural heart defects. The developmental outcomes and behavioral phenotypes of all 10 patients are summarized in Table 1. Severe speech and language impairment were common features in our patients (100\%) who were older than 1 year of age, and therefore capable of being evaluated for language development. Autistic-like behavior and other behavioral problems, such as self-stimulatory behavior, were also common features in our patients $(100 \%)$. 


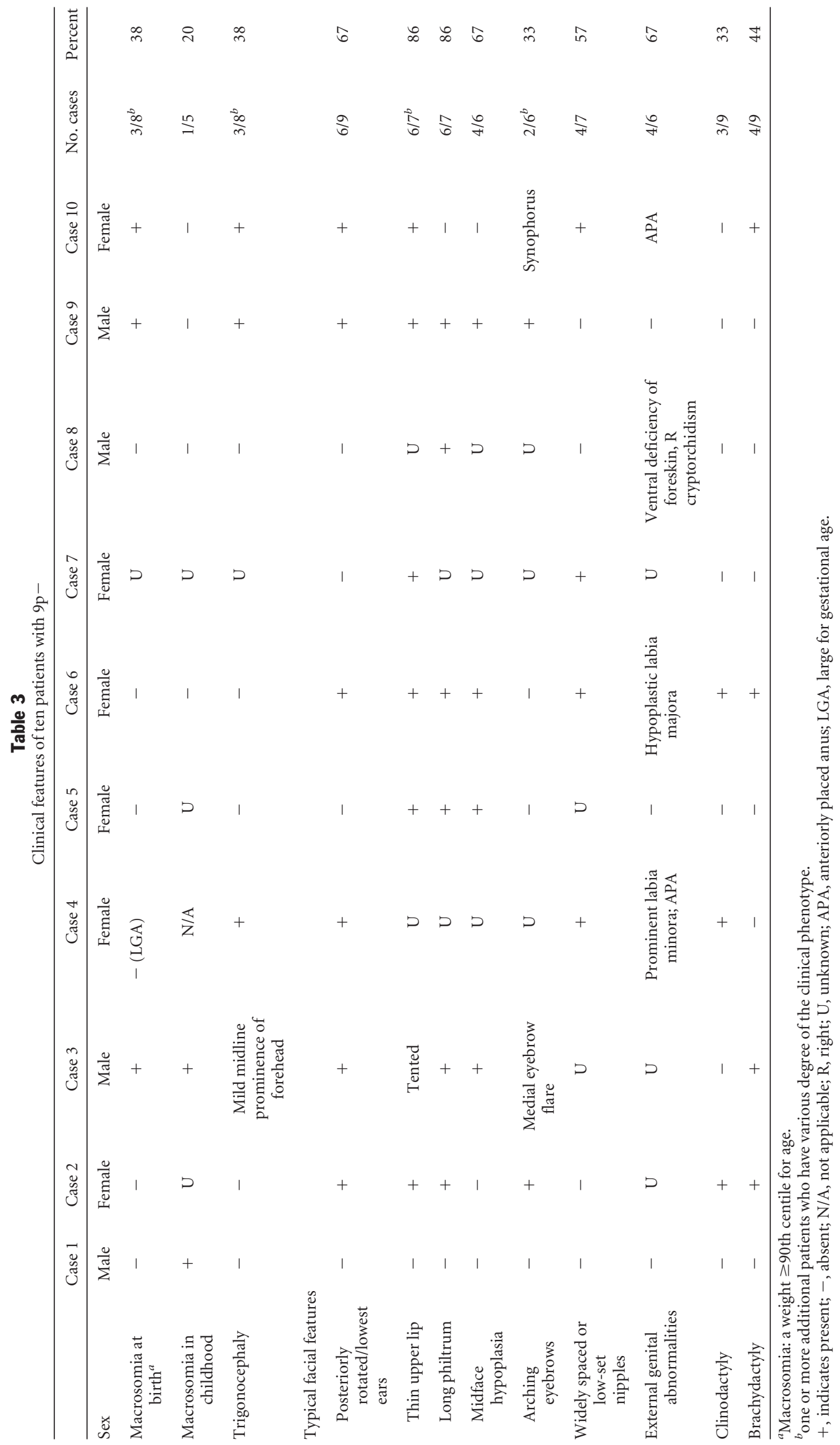




\section{Characterization of 9p deletion sizes}

G-banding analysis was initially performed on all $10 \mathrm{pa}-$ tients. Of these, five individuals had cytogenetically visible deletions involving breakpoints in band 9p23 or 9p24, whereas five individuals (Cases 1, 2, 3, 4, and 5) had deletions detected only by telomere FISH or aCGH. Four patients had pure, terminal deletions. Four cases had unbalanced translocations involving another chromosome: Cases 4 and 5 had monosomy of $9 p$ and trisomy of $15 q$ and $3 p$, respectively, whereas Cases 8 and 9 had monosomy of $9 p$ and trisomy of 20p. Case 6 had a terminal deletion of $9 p$ and an adjacent duplication of $9 p$. Case 1 had a small interstitial telomeric deletion.

Results from FISH and aCGH analyses are summarized graphically in Figure 2, with cases being arranged from the smallest to the largest deletions of $9 p$ (Cases 1-10). In addition, the molecular mapping methods utilized, minimum and maximum deletion sizes, and breakpoints in each case are summarized in Table 4. In Case 1, telomere FISH analysis indicated a $<420$-kb deletion of 9p with two telomere clones. aCGH analysis determined this telomeric deletion to be $140 \mathrm{~kb}$ in size and interstitial. Thirteen oligonucelotide probes spanning the entire DOCK 8 gene region (204,865-445,245 bp of 9p) were used on a custom array. Of these, seven oligonucleotide probes, from 235,823 to 304,969 bp, were deleted in Case 1 . Three probes that are located within the DOCK8 region, but $5^{\prime}$ to the deleted region were present. Thus, the DOCK 8 gene is partially deleted in Case 1, with a distal breakpoint at $230 \mathrm{~kb}$ from the end of the chromosome and a proximal breakpoint at $370 \mathrm{~kb}$ of 9pter. An independent FISH study using BAC RP11-910H2 (225-420 kb of 9pter) showed that the signal is reduced on one of the chromosome 9p whereas equal intensity of the signals of BAC RP11-106N6 (356-530 kb) were seen on both chromosomes 9 . Because the region up to $230 \mathrm{~kb}$ of 9 pter consists of mainly segmental duplicated sequences (Human Genome Browser Gateway, http://genome.ucsc.edu), FISH was used to confirm the array data using a clone located distal to the deleted region (BAC RP11-150N9). Two signals were observed on both chromosome nine homologs, verifying that Case 1 had an interstitial deletion. FISH and array analyses of this patient's mother showed that she also has the same deletion. Thus, the deletion is maternal in origin. Although the mother has had medical issues of her own, she does not have the same presentation, with the exception of seizures, as her son. This deletion is therefore most likely to be a benign copy number variant (CNV).

The remaining 9p deletions are all either de novo or inherited from a balanced carrier parent. Cases $1-6$ all had deletion

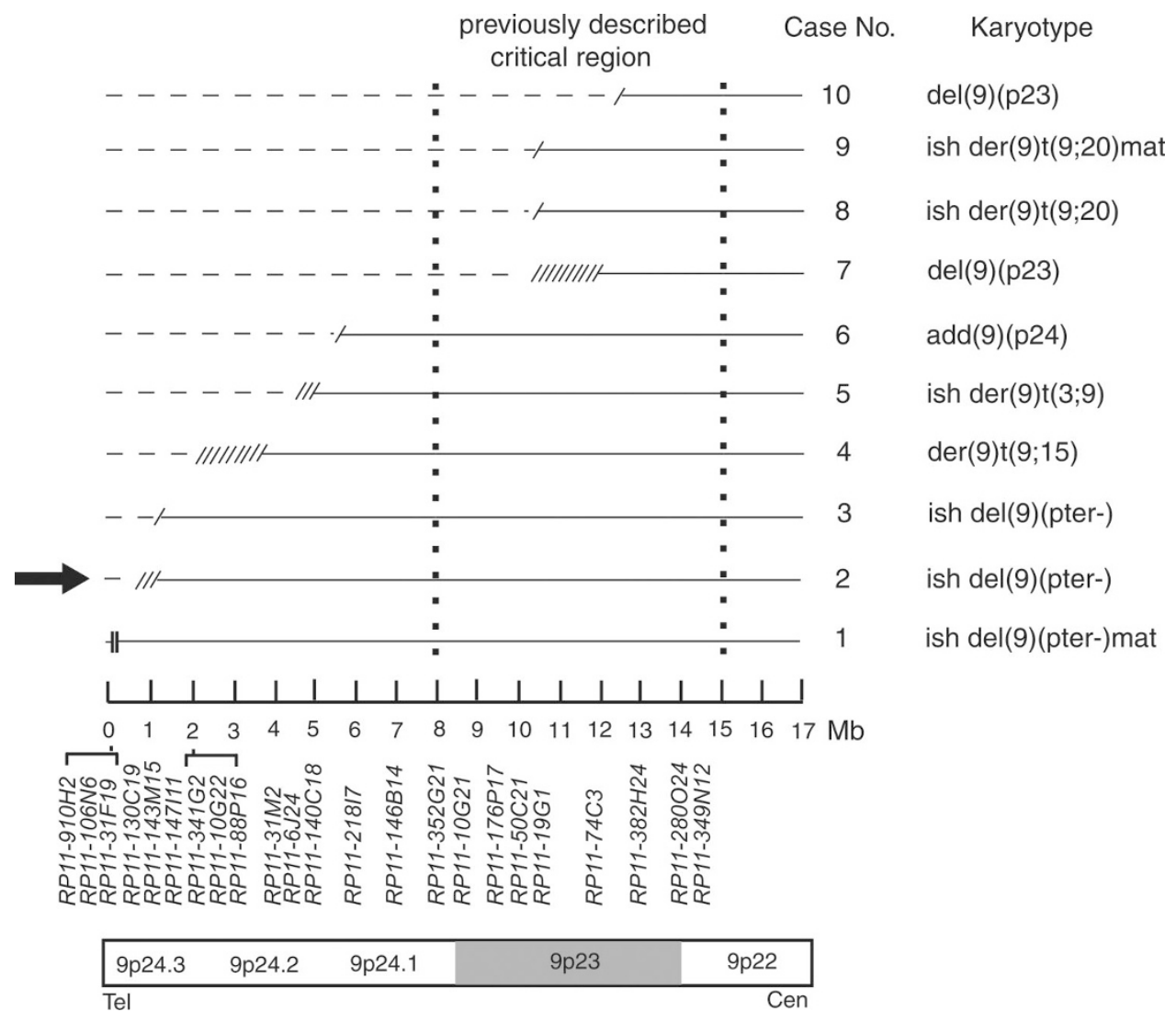

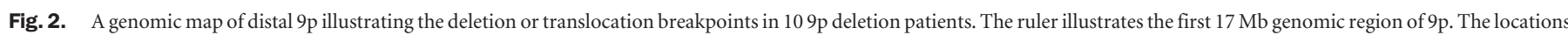

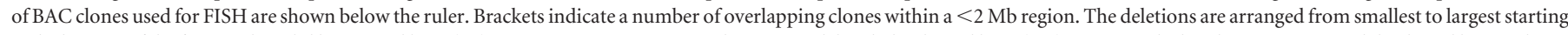

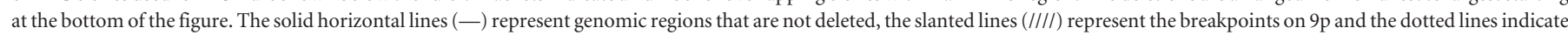

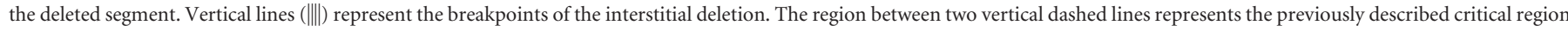
for $9 \mathrm{p}-$. The smallest deletion in our patients with clinically relevant phenotypes is indicated by an arrow. 


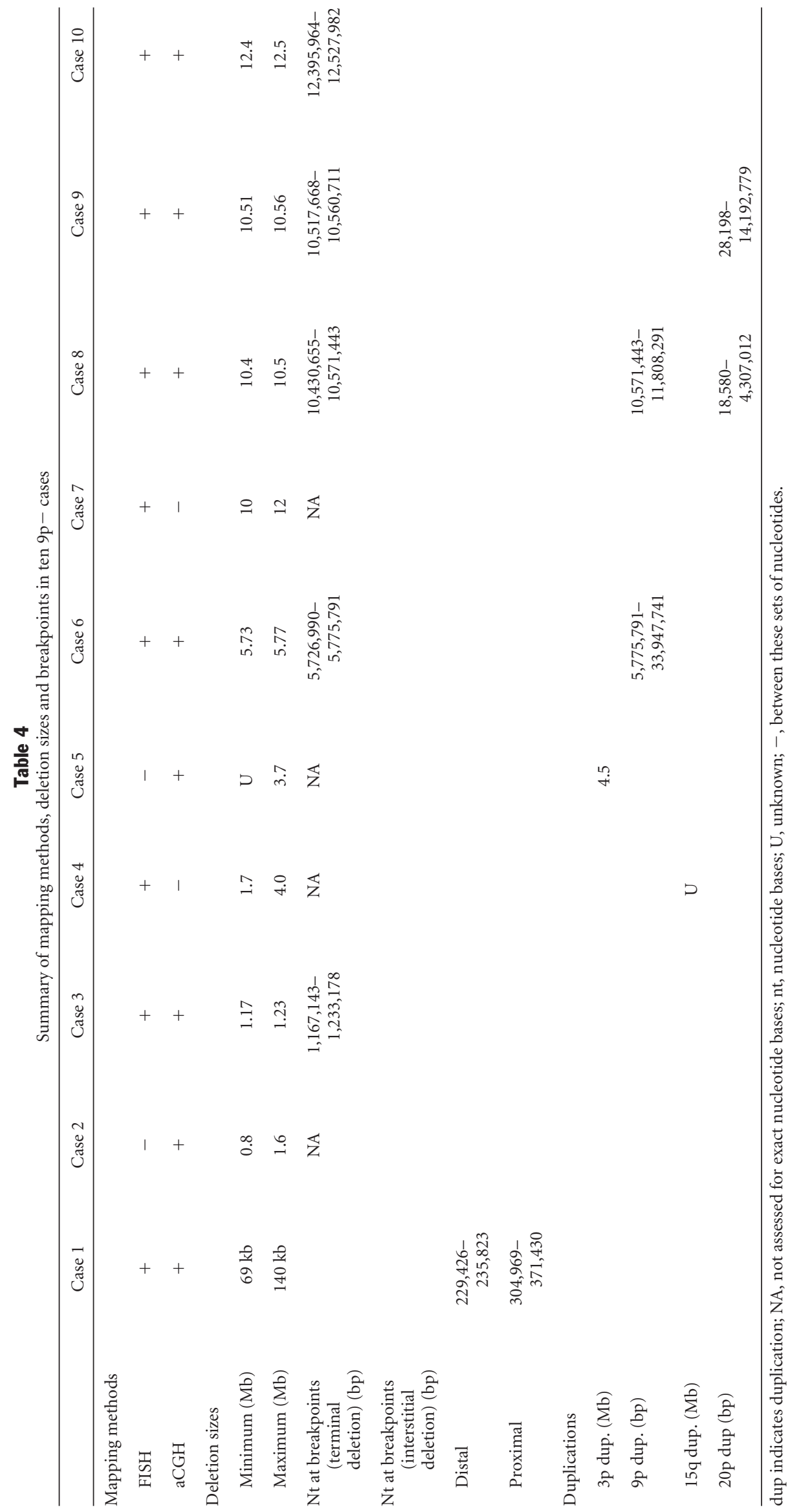




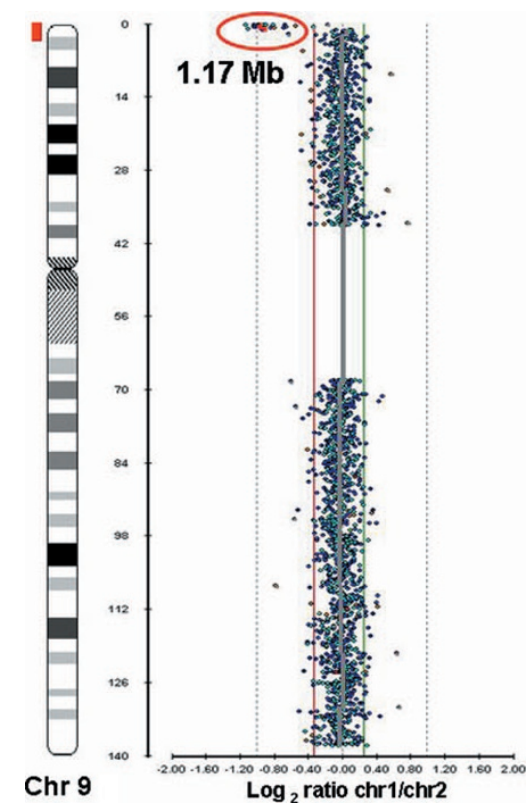

Fig. 3. Characterization of the breakpoints on $9 p$ in Case 3 using a custom oligonucleotide array. The chromosome ideogram is shown on the left of each panel. Each dot represents a single oligonucleotide. The area between the red and green lines represents the normal range of the ratio between the test and control DNA sample. The dots to the left of the red line represent a loss. Case 3 had a 1.17-Mb loss of $9 \mathrm{p}$ as demonstrated by aCGH.

breakpoints that were $<7 \mathrm{Mb}$ in size. Cases 2 and 3 are pure terminal deletions. Case 2 had a deletion breakpoint between $800 \mathrm{~kb}$ and $1.6 \mathrm{Mb}$, and Case 3 had a deletion breakpoint at $1.17 \mathrm{Mb}$ as shown in Figure 3. Cases 4 and 5 were unbalanced translocations. Case 4 had monosomy $9 \mathrm{p}$ and trisomy 15q. FISH analysis determined the size of the $9 \mathrm{p}$ deletion to be between 1.7 Mb and 4.0 Mb; by G-banding, the trisomic region of $15 q$ includes 15 q25-15qter. aCGH was not performed on Case 4 to further fine map these imbalances because there was no DNA sample available. Case 5 had monosomy $9 p$ and trisomy 3p. aCGH detected a 3.6-Mb deletion on the derivative 9 and a $4.5-\mathrm{Mb}$ duplication of 3p. Case 6 had a 5.7-Mb terminal deletion of $9 \mathrm{p}$ and a $28.3-\mathrm{Mb}$ duplication of $9 \mathrm{p}$. The duplicated segment included the region from $5.7 \mathrm{Mb}$ to $34 \mathrm{Mb}$ of 9 pter and was immediately adjacent to the deleted region detected by aCGH.

Cases 7-10 had breakpoints $>10 \mathrm{Mb}$ from the end of the chromosome. Case 7 had a deletion breakpoint between $10 \mathrm{Mb}$ and $12 \mathrm{Mb}$ of $9 \mathrm{p}$. There was no DNA sample from Case 7 available for aCGH analysis. Cases 8 and 9 both had unbalanced translocations between the short arms of $9 p$ and $20 p$. In Case 8, the unbalanced translocation resulted in monosomy for $10.4 \mathrm{Mb}$ of $9 \mathrm{p}$ and trisomy for $4.3 \mathrm{Mb}$ of the $20 \mathrm{p}$ telomere. In addition, a $1.2-\mathrm{Mb}$ duplication of $9 \mathrm{p}$, which was directly adjacent to the deleted region (encompassing the genomic region between 10.57-11.8 Mb), was also identified by aCGH. Case 9 had monosomy for $10.5 \mathrm{Mb}$ of $9 \mathrm{p}$ and trisomy for $14 \mathrm{Mb}$ of 20p. Lastly, aCGH showed that Case 10 had a $12.4-\mathrm{Mb}$ deletion of 9p. In all cases, the deletion breakpoints were unique.

\section{DISCUSSION}

Defining a minimal deleted region among patients with discrete phenotypes is a key step toward the identification of causative genes. Emerging techniques, such as aCGH, have allowed for escalation of these studies by more efficient mapping methods. There have been a number of studies aimed at characterizing the critical region of $9 \mathrm{p}$ deletion syndrome. ${ }^{2,5,8}$ Their combined results suggest that a $3.5-\mathrm{Mb}$ region between 11.4 $\mathrm{Mb}$ and $14.9 \mathrm{Mb}$ is the critical region, and genes within this region, such as CER1, are candidate genes. Nevertheless, many authors have lamented the lack of genotype-phenotype correlations, which is mainly a result of significant phenotypic diversity among the $9 p-$ patients and insufficient fine mapping data.

In our current study, FISH and aCGH analyses allowed us to calibrate the deletion or translocation breakpoints in 10 new patients with $9 \mathrm{p}$ deletions. Of these, nine patients have phenotypes consistent with $9 \mathrm{p}$-syndrome, whereas one patient, Case 1 , lacks the $9 \mathrm{p}-$ phenotype but possesses a small, maternally inherited interstitial deletion in the $9 p$ telomere region. His mother is developmentally normal and has a history of a seizure disorder, which resolved spontaneously. This deletion is therefore most likely to be a benign CNV. There have been four reported cases of benign variants of the 9pter region, which have been identified using the $9 \mathrm{p}$ telomere clone RP1$43 \mathrm{~N} 6$ (at $200 \mathrm{~kb}$ of 9pter): three cases were deletions, ${ }^{13-15}$ and one case was a duplication. ${ }^{15}$ Because phenotypically normal individuals show imbalances at $\sim 200 \mathrm{~kb}$ of 9 pter, this region can be excluded from the critical region of the $9 p-$ phenotype, since it would seem that genes in this region are tolerant to dosage changes.

Within our cohort, we found pure, terminal deletions in four cases and unbalanced translocations in four cases. A terminal deletion and a duplication of the adjacent DNA segment were found in one case. Although it is preferable to examine genotype-phenotype correlations based solely on data from patients with pure, terminal deletions, which eliminates interference from the trisomic region of another chromosome, one can still appreciate the cardinal features of $9 p-$ manifested by several unbalanced translocations in our study. For example, Case 9, who has an unbalanced translocation between $9 \mathrm{p}$ and $20 \mathrm{p}$, has a $9 \mathrm{p}-$ phenotype that includes trigonocephaly, lowset or malformed ears, thin upper lip, long philtrum, and thin and arching eyebrows (Fig. 1, B). Therefore, we included such individuals in our study, but analyzed pure deletions and unbalanced translocations separately. Phenotypic analysis suggests that macrosomia at birth and brachydactyly are more common in our patients with pure deletions $(67 \%$ and $75 \%$, respectively) than those with unbalanced translocations (20\% and $20 \%$, respectively). However, analysis in more cases is warranted. We saw no significant differences in other clinical features, such as dysmorphic facial features, postnatal major malformations, and speech and language delays, between these two types of imbalances. 
The breakpoints in the nine patients with pathogenic deletions can be divided into two groups: Cases 2-6 have deletions that are smaller than $7 \mathrm{Mb}$, and Cases 7-10 have deletions that are between 10 and $12.4 \mathrm{Mb}$ in size. Clinical evaluation and comparison of our patients showed little difference, in terms of deletion sizes, for the physical features that were evaluated. For instance, craniofacial abnormalities that are typically seen in $9 \mathrm{p}-$ syndrome, including trigonocephaly or prominence of forehead and low-set or malformed ears, were observed in both groups. Trigonocephaly was observed in three of our patients; one of these patients has a deletion that is smaller than $4 \mathrm{Mb}$, and the other two have deletions larger than $10 \mathrm{Mb}$ but smaller than $12.4 \mathrm{Mb}$. A fourth patient has midline prominence of the forehead. Gross motor skills do seem to be less severely impaired in the patients with the smaller deletions (e.g., Case 3) compared with the remaining individuals. However, careful analysis of more cases is warranted.

To establish correlations between the phenotype and genotype in our patients with $9 \mathrm{p}$ deletion syndrome, and identify potential candidate genes, we compared the minimally deleted regions of distal $9 p$ with the eight cardinal features of $9 p$ deletion syndrome. Figure 4 depicts the minimal deleted regions of the distal $9 \mathrm{p}$ and corresponding clinical features. We observed a correlation between the deletion of the first $2 \mathrm{Mb}$ of 9 pter and manifestations of the typical facial features, including low-set, malformed ears, thin upper lip, long philtrum, midface hyp- oplasia, and arching eyebrows. Importantly, these observations were made in patients with pure, terminal deletions of $9 \mathrm{p}$.

Trigonocephaly was observed with the deletion of the first 4 $\mathrm{Mb}$ of 9pter in one of our patients, Case 4. Although she also has a trisomy of $15 \mathrm{q}$, the latter is not known for causing the trigonocephaly phenotype. This observation differs from earlier reports, in which the critical region for trigonocephaly is mapped to a proximal region between $11.4 \mathrm{Mb}$ and $14.9 \mathrm{Mb}$. Trigonocephaly was also found in two patients with deletions larger than $10 \mathrm{Mb}$ but smaller than $12.4 \mathrm{Mb}$.

CER 1 has been proposed as a candidate gene for trigonocephaly. ${ }^{5}$ CER 1 plays a role in establishing the anterior-posterior axis in vertebrates ${ }^{16}$; however, studies have also shown that Cerr1, the mouse ortholog of CER1, is not essential for head formation, because no malformation of the head was detected in Cerr1 null mutants. ${ }^{17}$ The CER1 gene, located at $14.7 \mathrm{Mb}$ of $9 \mathrm{p}$, was not deleted in any of our patients with trigonocephaly, since deletions in these patients are smaller than $12.5 \mathrm{Mb}$ of $9 \mathrm{p}$. Thus, our data suggest that other genes or factors, contribute to the trigonocephaly observed in $9 \mathrm{p}$ deletion patients. One possibility is that deletions of the genomic region distal to CER1, for instance within 10-12 Mb of 9pter, may have indirect effects on the expression level of CER1, as shown in other syndromes, such as Williams-Beuren syndrome. ${ }^{18}$

Speech and language delays have rarely been reported in studies of $9 p-$ patients. Most of our $9 p-$ patients have severe

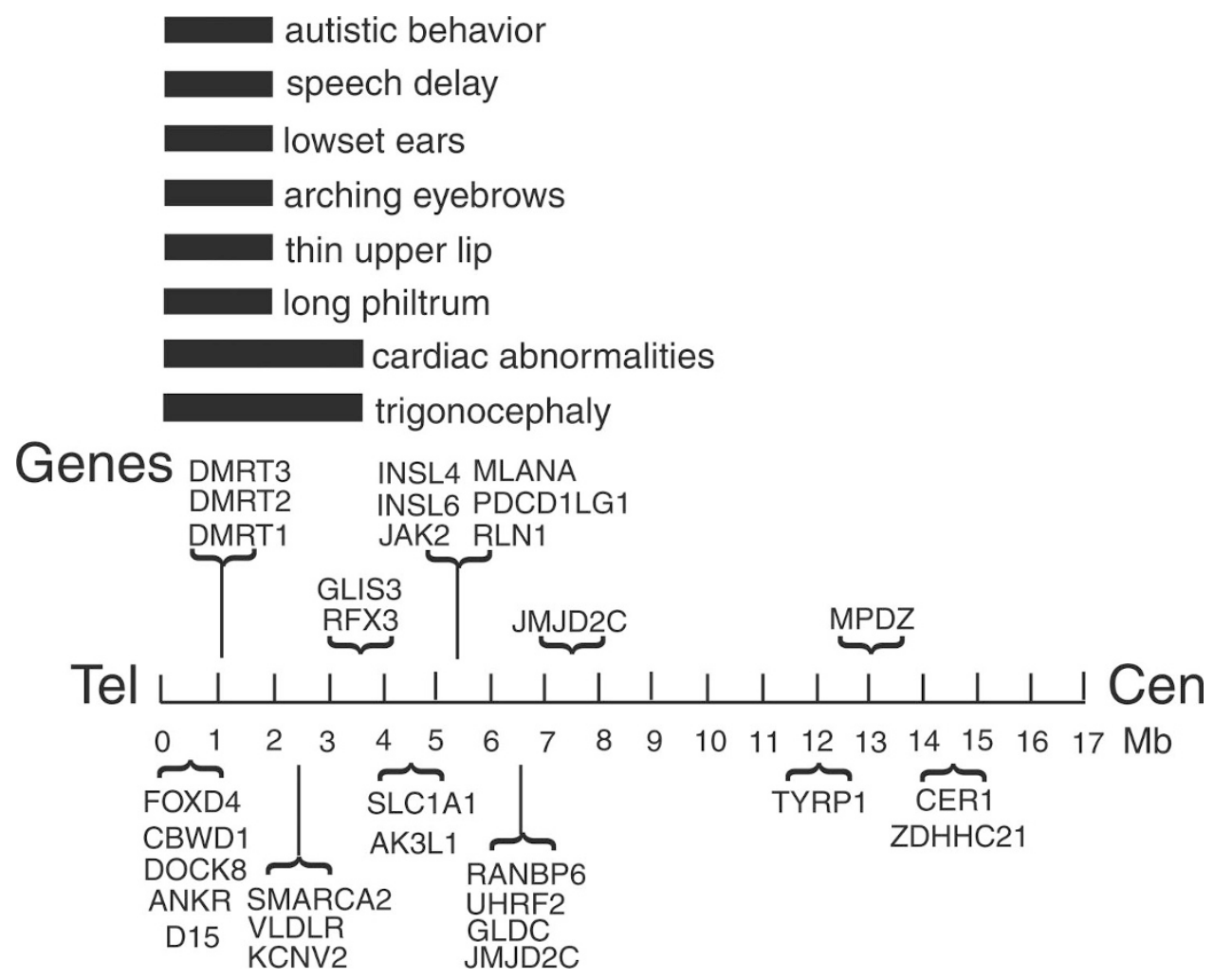

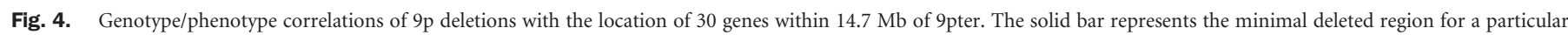

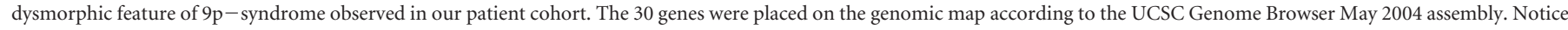
the higher gene density of the first $7 \mathrm{Mb}$ of $9 \mathrm{p}$, since $89 \%$ of the genes mapped to the most distal $14 \mathrm{Mb}$ of 9 pter are located within this $7 \mathrm{Mb}$ region. 
speech and language impairment, and sign language or the use of communication boards is a common form of expression. Autistic-like behaviors, in addition to significant speech delays and other behavioral problems, such as self-stimulatory behavior, were also observed. These patients share an $\sim 800 \mathrm{~kb}$ minimal deleted region of 9pter which contains FOXD4, located $100 \mathrm{~kb}$ from the $9 \mathrm{p}$ terminus. FOXD4 may be responsible for the speech and language deficits seen in our patients. In Case 1 and his normal mother, a 140-kb interstitial deletion (from 230 to $370 \mathrm{~kb}$ ) was detected by aCGH, which is most likely a benign $\mathrm{CNV}$. As a result, the first $230-\mathrm{kb}$ subtelomeric region of $9 \mathrm{p}$ is intact in these two individuals. FISH results further confirmed that both mother and son have two copies of the FOXD4 gene. The fact that Case 1 and his mother have no language and speech impairment comparable to those seen in $9 p$ deletion syndrome lends evidence to the contribution of the FOXD4 gene to speech and language development.

The FOXD4 gene belongs to the winged helix or forkhead transcription factor gene family and is highly conserved. ${ }^{19}$ The FOX gene family shares a $\sim 100$-amino-acid forkhead box (FOX) domain, which is indicative of DNA binding. Mutations of different forkhead genes have been linked to a range of disorders in humans and mice..$^{20}$ For example, a point mutation or truncation of one of the two copies of FOXP2, a member of the FOX gene family, causes impairment of neurological and motor development that leads to a distinctive form of speech and language disorder. ${ }^{21,22}$ Differential parent-of-origin expression of the FOXP2 gene has also been described in patients with the same speech and language disorder. ${ }^{23}$ FOXD4 is potentially a transcription factor and shares a crucial functional domain with FOXP2. Haploinsufficiency of FOXD4 may cause dosage imbalance in its target genes, which leads to abnormal development. The fact that most of our $9 p-$ patients, who have severe speech and language impairment, have a heterozygous deletion of FOXD4 suggests that FOXD4 may play a role in speech and language development or neurological development.

Abnormal external genitalia were present in several of our patients, but sex reversal was not observed in any of the three men with a 9p-phenotype (Cases 3, 8, and 9). Abnormalities of external genitalia vary significantly for individuals with a 46, $\mathrm{XY}$ karyotype, as described in several reports to date. ${ }^{7,24,25}$ Our finding is in agreement with the notion that deletion of the $D M R T$ genes alone is insufficient to cause sex reversal.

The DOCK8 gene, located $260-455 \mathrm{~kb}$ from the $9 \mathrm{p}$ telomere, has been proposed as a candidate gene for mental retardation. Griggs et al.,26 found that the DOCK8 gene is partially deleted or disrupted in two patients who demonstrated mental retardation. One of them also had no speech and seizures. ${ }^{26}$ Thus, the authors posit a putative role for DOCK8 in brain development and function. The DOCK8 gene is a potential guanine nucleotide exchange factor but its function remains unknown at this time. We demonstrated that the $5^{\prime}$ end of the DOCK8 gene is deleted in Case 1 and his normal mother, since the deleted region is between $230 \mathrm{~kb}$ and $370 \mathrm{~kb}$ of 9 pter, which suggests that it is not haploinsufficiency of the DOCK8 gene that leads to mental retardation and no speech. Nevertheless, deletion of DOCK8 may play a role in seizures, as both Case 1 and his normal mother have seizure disorders.

In summary, we have mapped the breakpoints of 10 patients with deletions of $9 p$, nine pathogenic and one benign $\mathrm{CNV}$, and correlated these findings to the clinical phenotypes of our patients. FISH and aCGH analyses showed that the minimal deleted region shared by our patients with clinically relevant phenotypes includes the first $2 \mathrm{Mb}$ of 9 pter. This deleted region of $9 p$, however, is distal to the previously described critical region. Therefore, it is likely that phenotypic features attributed to the $9 \mathrm{p}$-deletion syndrome may be caused by multiple regions on $9 p$ or other modifying factors in the genome. Furthermore, analysis of one benign variant case, Case 1, provided invaluable information. The analysis led us to narrow the minimum deleted region of $9 \mathrm{p}-$ syndrome by $140 \mathrm{~kb}$, to $<2 \mathrm{Mb}$, and allowed us to isolate two regions that are potentially responsible for speech and language development or neurological development and seizures. Twenty known genes are deleted in our patient who has a $9 p-$ phenotype with the largest deletion, whereas six known genes, including FOXD4 and DOCK8, are deleted in our patient with the smallest deletion and the $9 p-$ phenotype. These genes may contribute to some of the cardinal features of $9 \mathrm{p}$ deletion syndrome.

\section{ACKNOWLEDGMENTS}

This work was supported in part by the National Institutes of Health (R01 MH074090). The authors would like to thank Robert Wallerstein, Robert Hopkin, and Robin Wolf for providing patient samples and clinical information. We also thank Elijah Wallace, Josh Lowman, and Dr. Andrew Wong and the staff of the Emory Genetics Laboratory for technical assistance.

\section{References}

1. Huret JL, Leonard C, Forestier B, Rethore MO, Lejeune J. Eleven new cases of $\operatorname{del}(9 p)$ and features from 80 cases. J Med Genet 1988;25:741-749.

2. Christ LA, Crowe CA, Micale MA, Conroy JM, Schwartz S. Chromosome breakage hotspots and delineation of the critical region for the 9p-deletion syndrome. Am J Hum Genet 1999;65:1387-1395.

3. Flejter WL, Fergestad J, Gorski J, Varvill T, Chandrasekharappa S. A gene involved in $\mathrm{XY}$ sex reversal is located on chromosome 9, distal to marker D9S1779. Am J Hum Genet 1998;63:794-802.

4. Wagstaff J, Hemann M. A familial "balanced" 3;9 translocation with cryptic $8 \mathrm{q}$ insertion leading to deletion and duplication of 9p23 loci in siblings. Am J Hum Genet 1995;56:302-309.

5. Kawara H, Yamamoto T, Harada N, et al. Narrowing candidate region for monosomy 9p syndrome to a 4.7-Mb segment at 9p22.2-p23. Am J Med Genet A 2006;140: $373-377$.

6. Alfi O, Donnell GN, Crandall BF, Derencsenyi A, Menon R. Deletion of the short arm of chromosome no. 9 (46,9p-): a new deletion syndrome. Ann Genet 1973;16: $17-22$.

7. Muroya K, Okuyama T, Goishi K, et al. Sex-determining gene (s) on distal 9p: clinical and molecular studies in six cases. J Clin Endocrinol Metab 2000;85:30943100 .

8. Faas BH, de LN, Mieloo H, Bruinenberg J, de Vries BB. Further refinement of the candidate region for monosomy 9p syndrome. Am J Med Genet A 2007;143:2353-2356.

9. Ravnan JB, Tepperberg JH, Papenhausen P, et al. Subtelomere FISH analysis of 11 688 cases: an evaluation of the frequency and pattern of subtelomere rearrangements in individuals with developmental disabilities. J Med Genet 2006;43:478-489.

10. Lu X, Shaw CA, Patel A, et al. Clinical implementation of chromosomal microarray analysis: summary of 2513 postnatal cases. PLoS ONE 2007;2:e327.

11. Ballif BC, Sulpizio SG, Lloyd RM, et al. The clinical utility of enhanced subtelomeric coverage in array CGH. Am J Med Genet A 2007;143:1850-1857. 
12. Martin CL, Waggoner DJ, Wong A, et al. "Molecular rulers" for calibrating phenotypic effects of telomere imbalance. J Med Genet 2002;39:734-740.

13. Techakittiroj C, Kim KC, Andersson H, Li MM. 9p subtelomere deletion: pathogenic mutation or normal variant? Beijing Da Xue Xue Bao 2006;38:92-93.

14. Ballif BC, Kashork CD, Shaffer LG. The promise and pitfalls of telomere regionspecific probes. Am J Hum Genet 2000;67:1356-1359.

15. Iafrate AJ, Feuk L, Rivera MN, et al. Detection of large-scale variation in the human genome. Nat Genet 2004;36:949-951.

16. Biben C, Stanley E, Fabri L, et al. Murine cerberus homologue mCer-1: a candidate anterior patterning molecule. Dev Biol 1998;194:135-151.

17. Shawlot W, Min DJ, Wakamiya M, Behringer RR. The cerberus-related gene, Cerr1, is not essential for mouse head formation. Genesis 2000;26:253-258.

18. Merla G, Howald C, Henrichsen CN, et al. Submicroscopic deletion in patients with Williams-Beuren syndrome influences expression levels of the nonhemizygous flanking genes. Am J Hum Genet 2006;79:332-341.

19. Wong A, Vallender EJ, Heretis K, et al. Diverse fates of paralogs following segmental duplication of telomeric genes. Genomics 2004;84:239-247.

20. Crisponi L, Deiana M, Loi A, et al. The putative forkhead transcription factor
FOXL2 is mutated in blepharophimosis/ptosis/epicanthus inversus syndrome. Nat Genet 2001;27:159-166.

21. Lai CS, Fisher SE, Hurst JA, et al. The SPCH1 region on human 7q31: genomic characterization of the critical interval and localization of translocations associated with speech and language disorder. Am J Hum Genet 2000;67:357-368.

22. Fisher SE. Dissection of molecular mechanisms underlying speech and language disorders. Appl Psycholinguist 2005;26:111-128.

23. Feuk L, Kalervo A, Lipsanen-Nyman M, et al. Absence of a paternally inherited FOXP2 gene in developmental verbal dyspraxia. Am J Hum Genet 2006;79:965972.

24. Ogata T, Muroya K, Ohashi H, Mochizuki H, Hasegawa T, Kaji M. Female gonadal development in XX patients with distal 9p monosomy. Eur J Endocrinol 2001;145: 613-617.

25. Fujimoto Y, Okuyama T, Iijima M, et al. Genitourinary phenotype in XX patients with distal 9p monosomy. Mol Genet Metab 2004;82:173-179.

26. Griggs BL, Ladd S, Saul RA, DuPont BR, Srivastava AK. Dedicator of cytokinesis 8 is disrupted in two patients with mental retardation and developmental disabilities. Genomics 2007;91:195-202. 